\title{
Echinacea polysaccharide attenuates lipopolysaccharide-induced acute kidney injury via inhibiting inflammation, oxidative stress and the MAPK signaling pathway
}

\author{
QIUMEI SHI ${ }^{1}$, WUYING LANG ${ }^{2}$, SHIYONG WANG ${ }^{3}$, GUANGYU LI $^{4}$, \\ $\mathrm{XUE} \mathrm{BAI}^{4}, \mathrm{XIJUN} \mathrm{YAN}^{4}$ and HAIHUA ZHANG ${ }^{1}$ \\ ${ }^{1}$ College of Animal Science and Technology, Hebei Normal University of Science and Technology, Qinhuangdao, \\ Hebei 066004; ${ }^{2}$ College of Animal Science and Technology, Jilin Agricultural University, Changchun, Jilin 130118; \\ ${ }^{3}$ Institute of Laboratory Animal Science, Guizhou University of Traditional Chinese Medicine, Guiyang, \\ Guizhou 550025; ${ }^{4}$ Institute of Special Animal and Plant Sciences, Chinese Academy of Agricultural Sciences, \\ Changchun, Jilin 130112, P.R. China
}

Received February 29, 2020; Accepted August 26, 2020

DOI: $10.3892 / \mathrm{ijmm} .2020 .4769$

\begin{abstract}
Acute kidney injury (AKI) is often accompanied by inflammation. Echinacea polysaccharide (EP) is an active ingredient that has been demonstrated to possess anti-oxidative, anti-inflammatory, antimicrobial and immunomodulatory functions. However, the role of EP in AKI has not been examined. The present study investigated the effects of EP on lipopolysaccharide (LPS)-induced AKI. Western blotting, immunohistochemistry and immunofluorescence analyses were performed to detect protein expression levels. Administration of EP significantly attenuated LPS-induced renal tissue injury, along with a decrease in blood urea nitrogen and creatinine levels. EP decreased the levels of inducible nitric oxide synthase and cyclo-oxygenase-2 in LPS-treated mice. Furthermore, LPS-induced inflammation was inhibited by EP in renal tissues and HBZY-1 cells, as demonstrated by
\end{abstract}

Correspondence to: Dr Haihua Zhang, College of Animal Science and Technology, Hebei Normal University of Science and Technology, 360 West Section, Hebei Avenue, Qinhuangdao, Hebei 066004, P.R. China

E-mail: tcszhh83@163.com

Abbreviations: EP, Echinacea polysaccharide; LPS, lipopolysaccharide; AKI, acute kidney injury; H\&E, hematoxylin and eosin; PAS, periodic acid-Schiff; BUN, blood urea nitrogen; $\mathrm{Cr}$, creatinine; TNF- $\alpha$, tumor necrosis factor- $\alpha$; IL, interleukin; NO, nitric oxide; PGE2, prostaglandin E2; iNOS, inducible nitric oxide synthase; COX-2, cyclo-oxygenase-2; OS, oxidative stress; ROS, reactive oxygen species; MDA, malondialdehyde; $S O D$, superoxide dismutase; CAT, catalase; GR, glutathione reductase; GSH, reduced glutathione; GSSG, oxidized glutathione; MAPK, mitogen-activated protein kinase; ERK, extracellular signal-regulated protein kinase; JNK, c-Jun N-terminal kinase; p-, phospho-

Key words: AKI, EP, inflammation, OS, MAPK signaling pathway the downregulation of tumor necrosis factor- $\alpha$, interleukin (IL)-1 $\beta$, IL-6, nitric oxide and prostaglandin E2 levels. Similarly, EP administration decreased oxidative stress (OS) via decreasing reactive oxygen species, malondialdehyde and oxidized glutathione levels, and increasing superoxide dismutase, catalase, glutathione reductase and reduced glutathione activity. Notably, EP induced a marked decrease in the expression levels of phospho-extracellular signal-regulated protein kinase (p-ERK), phospho-c-Jun N-terminal kinase (p-JNK) and p-p38 in vivo and in vitro. In addition, in LPS-treated HBZY-1 cells, EP enhanced cell viability and inhibited nuclear translocation of p-ERK, p-JNK and p-p38. Overall, the present findings demonstrated that EP alleviated LPS-induced AKI via the suppression of inflammation, OS and the mitogen-activated protein kinase signaling pathway, providing insight into potential avenues for the treatment of AKI.

\section{Introduction}

Acute kidney injury (AKI), a common complication observed in critically ill patients admitted to the intensive care unit, is characterized by a sharp and sustained decline in renal function during a short period of time $(1,2)$. The occurrence of AKI was estimated to be 13 million cases worldwide in 2016, and AKI results in $\sim 1.7$ million deaths per year (3). Lipopolysaccharide (LPS), an endotoxin from the outer membrane of gram-negative bacteria, has been widely used to induce AKI-associated pathologies, including inflammation and oxidative stress (OS) $(4,5)$. LPS has been reported to mediate both systemic and renal inflammation through signaling by recognition of Toll-like receptor 4, which is present on immune and proximal tubule epithelial cells (2). At present, there are no targeted strategies for the treatment of AKI, and the underlying mechanisms of development are incompletely understood. Therefore, it is necessary to find effective drugs to treat AKI and understand its molecular mechanisms. 
Increasing evidence has demonstrated that traditional Chinese medicine may prevent or ameliorate AKI (6-8). Echinacea (Asteraceae) is frequently utilized in North America and Europe to prevent and treat the common cold (9). Root preparations of Echinacea purpurea (E. purpurea) and $E$. angustifolia have been applied to promote wound healing and treat burns, and are widely used as an ingredient of cosmetic or antimicrobial preservatives, or as a functional food ingredient (10-12). In vitro studies have suggested that Echinacea may act directly on monocytes, natural killer cells, human keratinocytes and macrophages $(11,13,14)$. Additionally, E. purpurea extract has been employed as a prophylactic for treatment of a range of viral infections, particularly for respiratory tract infections in animals and humans (15). Pharmacological studies have emphasized the immunomodulatory activities of cichoric acid, alkamides and polysaccharides from E. purpurea $(13,14,16)$. The immunostimulant effect of E. purpurea appears to be due to polysaccharides surrounding tissue cells that protect against pathogenic invasion (14), suggesting that polysaccharides may serve as the primary active factor associated with the anti-inflammatory effects of E. angustifolia. Aarland et al (17) reported that E. purpurea and $E$. angustifolia exhibited anti-oxidative, anti-inflammatory and anti-proliferative effects in vitro. Additionally, it was demonstrated that $E$. purpurea polysaccharide exhibited antiviral properties in herpes simplex virus type-1 infections (14). Accordingly, the present study hypothesized that E. purpurea polysaccharide (EP) may be used to treat LPS-induced AKI.

Mitogen-activated protein kinases (MAPKs) are a family of serine-threonine protein enzymes that control several physiological processes including cell proliferation, apoptosis, inflammation and OS $(18,19)$. The MAPK signaling pathway primarily encompasses three signaling cascades: Extracellular signal-regulated kinase (ERK), c-Jun-N-terminal kinase (JNK) and p38 (18). A previous study demonstrated that a novel polysaccharide derived from algae extracts inhibited proliferation and induced apoptosis, as well as cell cycle arrest, of breast cancer cells (MCF-7 cells) via the JNK signaling pathway (20). Additionally, Sherif et al (21) revealed that the MAPK signaling pathway was closely associated with the occurrence and development of AKI. For example, the suppression of the MAPK signaling pathway by baicalein (a bioflavonoid) prevented cisplatin-induced AKI (22). Another study demonstrated that polygonatum sibiricum polysaccharides improved gentamicin-mediated AKI in rats via repressing p38 in the MAPK signaling pathway (23). However, whether EP can attenuate LPS-induced AKI via inhibition of the MAPK signaling pathway has not been determined.

The aim of the present study was to investigate the underlying mechanism by which EP alleviated AKI using in vivo and in vitro models. HBZY-1 cells have been intensively utilized as a cell model in LPS-induced inflammation in accordance with previous studies $(24,25)$. Therefore, HBZY-1 cells were used in the present study to establish an in vitro model to evaluate the role of EP in inflammatory responses mediated by LPS. The current results revealed that LPS-induced AKI was attenuated by EP via inhibition of inflammation, OS and the activation of the MAPK signaling pathway, suggesting that EP may be used as a potential therapeutic for the treatment of AKI.

\section{Materials and methods}

Materials. LPS was provided by Shanghai Aladdin Biochemical Technology Co., Ltd. EP was purchased from Nanjing Daosifu Biological Technology Co., Ltd., extracted from Echinacea purpurea Moench with a purity of $90.26 \%$. EP was diluted using DMSO for both the in vivo and in vitro experiments. For the in vivo experiments, C57BL/6 mice were supplied by Liaoning Changsheng Biotechnology Co., Ltd. HBZY-1 cells were obtained from Procell Life Science \& Technology Co., Ltd..

Mouse model of LPS-induced AKI. To establish a mouse model of AKI, 8-week-old male C57BL/6 mice (30 mice; weight, $20 \mathrm{~g}$ ) underwent an acclimatization period for a week (living conditions: 12 -h light/dark cycle, $25 \pm 1{ }^{\circ} \mathrm{C}, 45-55 \%$ humidity and ad libitum access to food and water). Mice were randomly divided into five groups ( $\mathrm{n}=6$ per group), including a control group (without treatment), $10 \mathrm{mg} / \mathrm{kg}$ EP group, LPS group, LPS $+5 \mathrm{mg} / \mathrm{kg}$ EP group and LPS $+10 \mathrm{mg} / \mathrm{kg}$ EP group. Mice were given an intraperitoneal injection of LPS $(10 \mathrm{mg} / \mathrm{kg})$ alone or followed by an intravenous injection of EP (5 or $10 \mathrm{mg} / \mathrm{kg}$ ); the concentrations used were based on previous studies $(14,26)$. After $24 \mathrm{~h}$ from injection, mice were anesthetized via intraperitoneal injection of sodium pentobarbital (50 mg/kg). Peripheral blood samples (1-1.5 ml per mouse) were collected from mice with the eyeball removed in the animal experiment room, and mice were euthanized (weight, $22-24 \mathrm{~g}$ ) using $200 \mathrm{mg} / \mathrm{kg}$ sodium pentobarbital. Renal tissues were collected and either fixed in $4 \%$ paraformaldehyde at $4^{\circ} \mathrm{C}$ for $15 \mathrm{~min}$ or frozen at $-70^{\circ} \mathrm{C}$. All animal studies and protocols were approved by the Animal Care Committee of Hebei Normal University of Science and Technology (approval no. 201823; 5 September 2018) and performed in accordance with the Committee's guidelines on animal care.

Histopathological evaluation. Fixed renal tissues were embedded in paraffin and cut into $5-\mu \mathrm{m}$-thick sections. For hematoxylin and eosin (H\&E) staining, the sections were deparaffinized in xylene at room temperature (RT) and stained with hematoxylin (Sangon Biotech Co., Ltd.) for $5 \mathrm{~min}$ and eosin (Beijing Solarbio Science \& Technology Co., Ltd.) for $3 \mathrm{~min}$, both at RT. For periodic acid-Schiff (PAS) staining, tissues were cut into $5-\mu \mathrm{m}$-thick sections. After deparaffinizing the sections as aforementioned, the tissues were stained with periodic acid for $10 \mathrm{~min}$ and counterstained with Schiff for $15 \mathrm{~min}$, both at RT, using a PAS staining solution obtained from BaSO Biotech Co., Ltd.. All the sections were observed using a fluorescence microscope (Olympus Corporation; magnification, x200 for H\&E and x400 for PAS). Inflammation was scored on a scale from 0 to 4 : 0 , None; 1 , rare; 2 , common; 3 , frequent; and 4 , severe (27). PAS-positive cells were quantified using Image Pro-Plus v6.0 (Media Cybernetics, Inc.).

Serum analysis. After $24 \mathrm{~h}$ of EP and LPS treatment, blood samples were collected, and the levels of blood urea nitrogen (BUN) and creatinine (Cr) were determined using BUN and $\mathrm{Cr}$ detection kits (Nanjing Jiancheng Bioengineering Institute) according to the manufacturer's protocol. BUN levels were measured at a wavelength of $640 \mathrm{~nm}$, while Cr levels at a 
wavelength of $510 \mathrm{~nm}$ using a UV-visible spectrophotometer (Shanghai Yoke Instrument Co., Ltd.).

Immunohistochemistry. Paraffin-embedded 5- $\mu$ m-thick renal tissue sections were deparaffinized with xylene for $30 \mathrm{~min}$ at RT and rehydrated in a descending alcohol series $(95,85$ and $75 \%$ ). After antigen retrieval, sections were incubated with $3 \% \mathrm{H}_{2} \mathrm{O}_{2}$ at room temperature for $15 \mathrm{~min}$ and blocked with goat serum (Beijing Solarbio Science \& Technology Co., Ltd.) for 15 min at RT. Sections were incubated with primary antibodies against inducible nitric oxide synthase (iNOS; 1:100; cat. no. 18985-1-AP; ProteinTech Group, Inc.) or cyclo-oxygenase-2 (COX-2; 1:100; cat. no. ab133466; Abcam) overnight at $4^{\circ} \mathrm{C}$, and subsequently incubated with a biotin-labeled goat anti-rabbit IgG secondary antibody (1:200; cat. no. A0277; Beyotime Institute of Biotechnology) at $37^{\circ} \mathrm{C}$ for $30 \mathrm{~min}$. The slides were labeled with horseradish peroxidase enzyme (Beyotime Institute of Biotechnology), stained with DAB (Beijing Solarbio Science \& Technology Co., Ltd.) and counterstained with hematoxylin for $3 \mathrm{~min}$ at RT. All sections were observed under a fluorescence microscope (Olympus Corporation) at a magnification of $\mathrm{x} 400$ and quantified using Image Pro-Plus v6.0.

LPS-induced HBZY-1 cell model. HBZY-1 cells were cultured in DMEM (Procell Life Science \& Technology Co., Ltd.) containing $10 \%$ FBS (Biological Industries) at $37^{\circ} \mathrm{C}$ in a humidified incubator with $5 \% \mathrm{CO}_{2}$. Cells $\left(3 \times 10^{3} /\right.$ well) were seeded in a 96-well plate and cultured for $24 \mathrm{~h}$. Cells were pretreated with EP $(100 \mu \mathrm{g} / \mathrm{ml})$, PD98095 (ERK inhibitor; $50 \mu \mathrm{mol} / 1$; Selleck Chemicals), SP600125 (JNK inhibitor; $10 \mu \mathrm{mol} / \mathrm{l}$; MedChemExpress) or SB203580 (p38 inhibitor; $10 \mu \mathrm{mol} / \mathrm{l}$; MedChemExpress) for $1 \mathrm{~h}$ and then stimulated with LPS $(1 \mu \mathrm{g} / \mathrm{ml})$ for $24 \mathrm{~h}$, all at $37^{\circ} \mathrm{C}$.

Cell viability assay. Cell viability was assessed after treatment with EP and/or LPS using an MTT assay (Sigma-Aldrich; Merck KGaA). MTT $(0.5 \mathrm{mg} / \mathrm{ml} ; 100 \mu \mathrm{l})$ was added to each well, and cells were cultured at $37^{\circ} \mathrm{C}$ with $5 \% \mathrm{CO}_{2}$ for $4 \mathrm{~h}$. DMSO $(150 \mu \mathrm{l})$ was added to the cells to solubilize the formazan crystals for $10 \mathrm{~min}$ at RT in the dark. The absorbance was measured at $570 \mathrm{~nm}$ using a microplate reader (BioTek Instruments, Inc.).

Detection of inflammatory cytokines. The levels of tumor necrosis factor (TNF)- $\alpha$, interleukin (IL)-1 $\beta$ and IL- 6 were evaluated using commercial ELISA kits (Wuhan USCN Business Co., Ltd.), including a TNF- $\alpha$ detection kit (cat. no. SEA133Mu), IL-1 $\beta$ detection kit (cat. no. SEA563Mu) and IL-6 detection kit (cat. no. SEA079Mu). Briefly, renal tissues and cell supernatants by centrifugation $(1,000 \mathrm{x} \mathrm{g}$ for $20 \mathrm{~min}$ at RT) were collected after treatment with EP and/or LPS. The concentrations of the proteins were determined using a bicinchoninic acid (BCA) kit (Beyotime Institute of Biotechnology). Subsequently, samples were analyzed using the corresponding kits according to the manufacturer's protocols, and the absorbance was measured at a wavelength of $450 \mathrm{~nm}$ using a microplate reader (BioTek Instruments, Inc.).

Determination of nitric oxide (NO) levels. NO content in renal tissues was detected using a microwell plate method (5) and an NO assay kit (cat. no. A013-2; Nanjing Jiancheng Bioengineering Institute) according to the manufacturer's protocol. The absorbance was measured at a wavelength of $550 \mathrm{~nm}$ using a microplate reader (BioTek Instruments, Inc.).

Determination of prostaglandin E2 (PGE2). The levels of PGE2 in renal tissues were detected using a PGE2 detection kit (cat. no. CEA538Ge; Wuhan USCN Business Co., Ltd.) according to the manufacturer's protocol. The absorbance was measured at a wavelength of $450 \mathrm{~nm}$ using a microplate reader (BioTek Instruments, Inc.).

Measurement of reactive oxygen species (ROS) production. The production of ROS was assessed using a ROS detection kit (cat. no. E004; Nanjing Jiancheng Bioengineering Institute). Briefly, kidney tissues or cells after treatment with EP and/or LPS were washed with PBS twice and incubated with dichloro-dihydro-fluorescein diacetate (DCFH-DA; $10 \mu \mathrm{mol} / \mathrm{l}$ ) at $37^{\circ} \mathrm{C}$ for $30 \mathrm{~min}$ in the dark. After washing with PBS, ROS generation was observed using a fluorescence microplate reader (Tecan Group, Ltd.).

Biochemical assays. The levels of malondialdehyde (MDA), superoxide dismutase (SOD), catalase (CAT), reduced glutathione (GSH) and oxidized glutathione (GSSG) were measured using specific kits (Nanjing Jiancheng Bioengineering Institute), including MDA detection kit (cat. no. A003-1), SOD detection kit (cat. no. A001-1), CAT detection kit (cat. no. A007-1) and T-GSH/GSSG detection kit (cat. no. A061-1). In addition, the activity of glutathione reductase (GR) was assessed using a GR detection kit (cat. no. BC1160; Beijing Solarbio Science \& Technology Co., Ltd.). Briefly, renal tissues and cells after treatment with EP and/or LPS were prepared by centrifugation (tissues at $420 \mathrm{xg}$ for $10 \mathrm{~min}$ and cells at 1,500 $\mathrm{g}$ for $10 \mathrm{~min}$, both at RT). The concentrations of collected supernatants were determined using a BCA kit. The absorbance of the samples was detected according to the manufacturers' instructions of the aforementioned detection kits using a microplate reader (BioTek Instruments, Inc.).

Western blotting. Kidney tissues and treated cells were lysed using RIPA lysis buffer (Beyotime Institute of Biotechnology). The protein concentrations were quantified using a BCA kit. A total of $20 \mu \mathrm{g}$ protein/lane was separated via SDS-PAGE (5, 8 or $10 \%$ gel) and transferred to a PVDF membrane (Thermo Fisher Scientific, Inc.). After blocking non-specific binding sites with 5\% BSA (Biosharp Life Sciences) dissolved in TBS-Tween $(0.15 \%$ Tween 20$)$ for $1 \mathrm{~h}$ at RT, the membranes were incubated with primary antibodies against $\beta$-actin (1:2,000 in 5\% BSA; cat. no. 60008-1-Ig), iNOS (1:500; cat. no. 18985-1-AP) and COX-2 (1:300; cat. no. 12375-1-AP) from ProteinTech Group, Inc.; phospho-(p-)ERK (Thr202/Tyr204; 1:1,000; cat. no. AF1015) and ERK (1:2,000; cat. no. AF0155) from Affinity Biosciences; and p-JNK (Thr183/Tyr185; 1:1,000; cat. no. 4668), JNK (1:1,000; cat. no. 9252), p-p38 (Thr180/Tyr182; 1:1,000; cat. no. 4511) and p38 (1:1,000; cat. no. 8690) from Cell Signaling Technology, Inc., overnight at $4^{\circ} \mathrm{C}$. $\beta$-actin was used as the internal reference. Subsequently, membranes were incubated with goat anti-rabbit IgG-HRP (1:5,000; cat. no. SA00001-2; ProteinTech Group, Inc.) or 
A
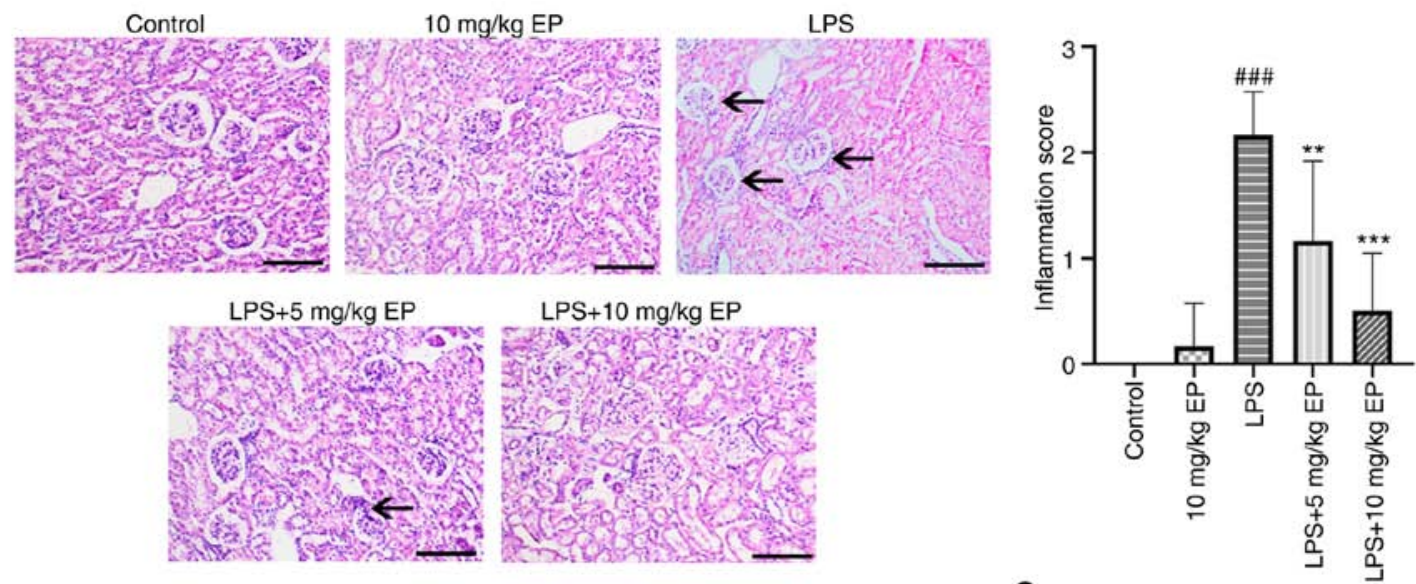

B
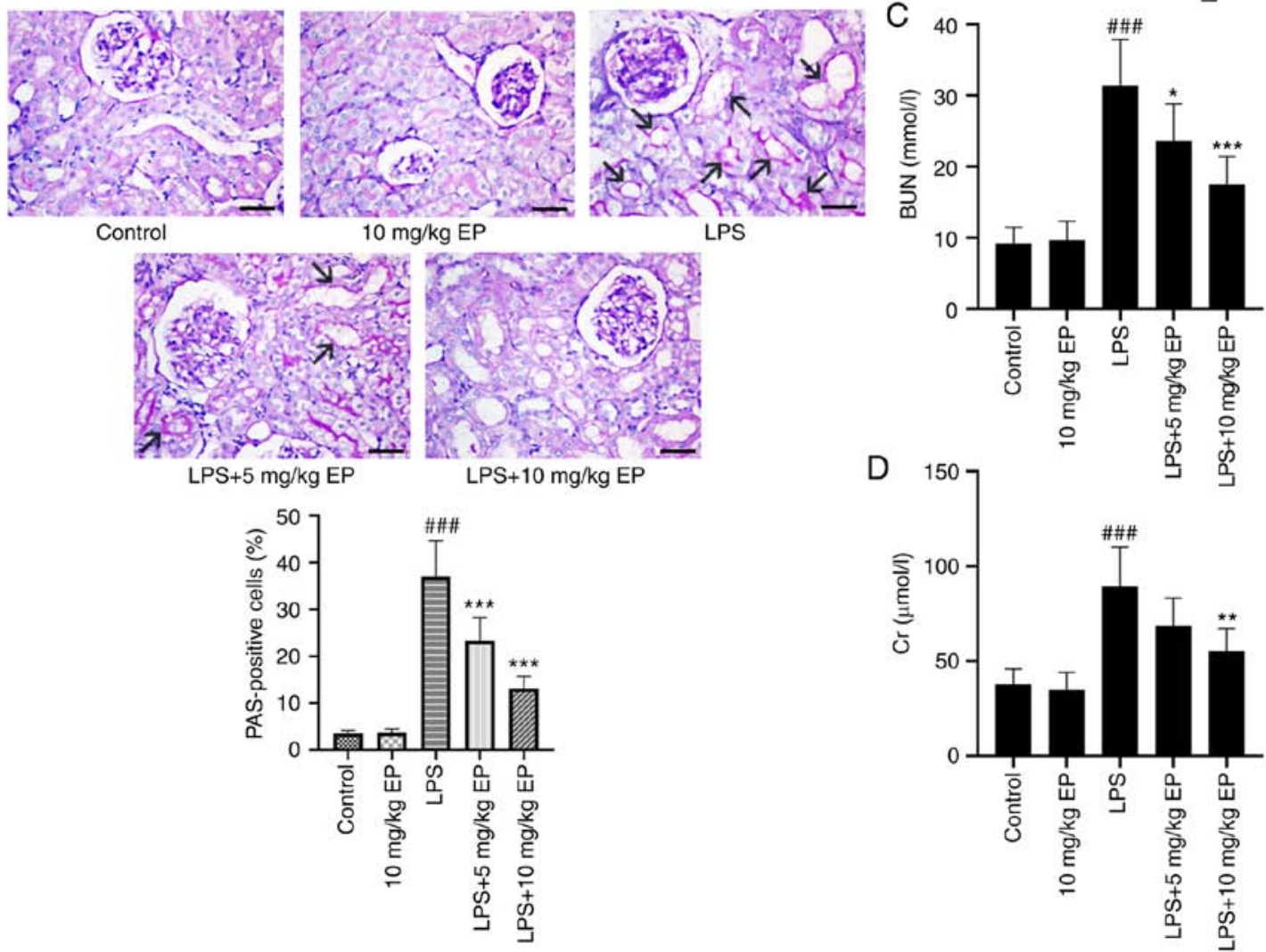

Figure 1. Effect of EP on acute renal injury induced by LPS. Morphological changes in renal tissues were detected using (A) hematoxylin and eosin staining (scale bar, $100 \mu \mathrm{m}$ ) and (B) periodic acid-Schiff staining (scale bar, $50 \mu \mathrm{m}$ ). Horizontal arrows represent inflammation. Oblique arrows represent PAS-positive cells. (C) BUN and (D) Cr levels in the blood of mice in each group. Results are presented as the mean \pm standard deviation $(\mathrm{n}=6)$. ${ }^{\# \# \#} \mathrm{P}<0.001$ vs. control group; ${ }^{*} \mathrm{P}<0.05,{ }^{* *} \mathrm{P}<0.01$ and ${ }^{* * *} \mathrm{P}<0.001$ vs. LPS group. EP, Echinacea polysaccharide; LPS, lipopolysaccharide; BUN, blood urea nitrogen; $\mathrm{Cr}$, creatinine.

goat anti-mouse IgG-HRP (1:5,000; cat. no. SA00001-1; ProteinTech Group, Inc.), both diluted in $5 \%$ BSA, at $37^{\circ} \mathrm{C}$ for $40 \mathrm{~min}$. The signals were visualized using an enhanced chemiluminescent reagent (cat. no. E002-100; Shanghai Qihai Futai Biological Technology Co., Ltd.) and quantified using Gel-Pro Analyzer v4.0 (Media Cybernetics, Inc.).

Immunofluorescence analysis of HBZY-1 cells. Cells were grown on slides and treated with EP and/or LPS. Subsequently, cells were fixed using $4 \%$ paraformaldehyde for $15 \mathrm{~min}$ at $4^{\circ} \mathrm{C}$, washed three times with PBS (5 min per wash) and incubated with $0.1 \%$ Triton X-100 (Beyotime Institute of Biotechnology) for $30 \mathrm{~min}$ at RT. After washing three times with PBS, the slides were blocked using goat serum (cat. no. SL038; Beijing Solarbio Science \& Technology Co., Ltd.) for $15 \mathrm{~min}$ at RT and incubated with primary antibodies against p-ERK (1:200; cat. no. AF1015; Affinity Biosciences), p-JNK (1:200; cat. no. bs-1640R; BIOSS) and p-p38 (1:200; cat. no. bs-0636R; BIOSS) overnight at $4^{\circ} \mathrm{C}$. Cells were incubated with a Cy3-labeled goat anti-rabbit IgG secondary antibody (1:200; cat. no. A0516; Beyotime Institute of Biotechnology) for $1 \mathrm{~h}$ at RT and counterstained with DAPI (Beyotime Institute of Biotechnology) for $3 \mathrm{~min}$ at RT. Cells were visualized using a fluorescence microscope (magnification, $\mathrm{x} 400$ ).

Statistical analysis. The data are expressed as the mean \pm standard deviation. All data analyses were performed 
A
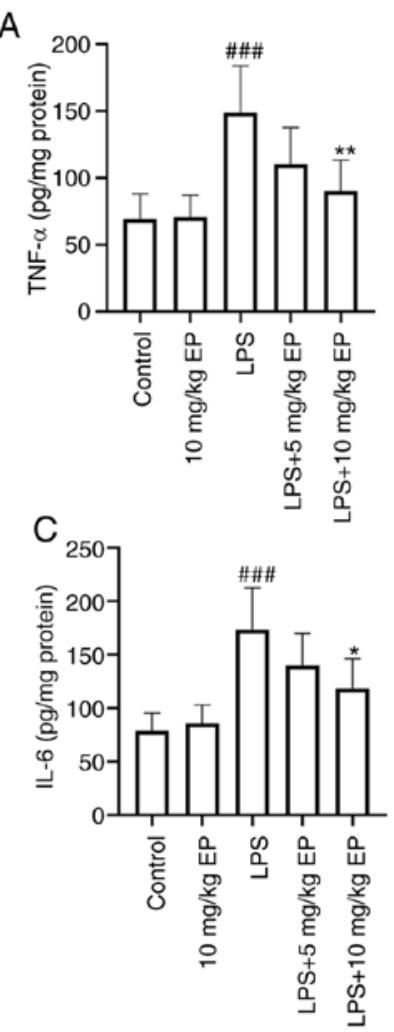
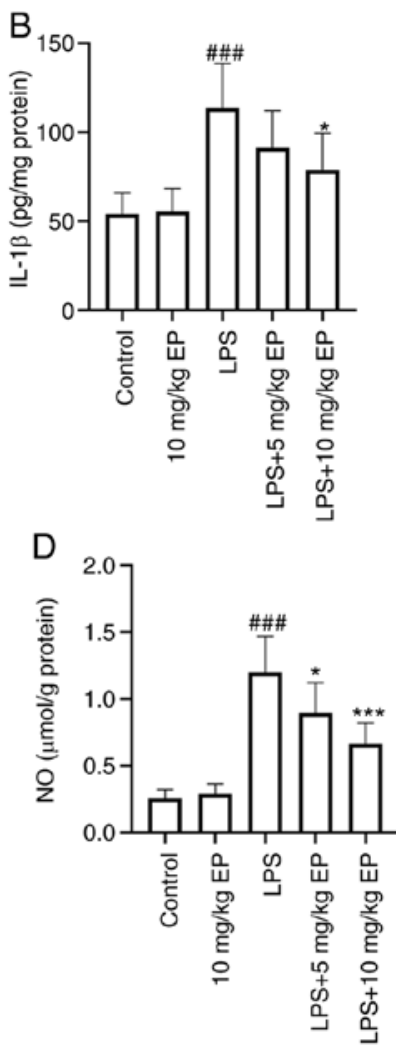

E
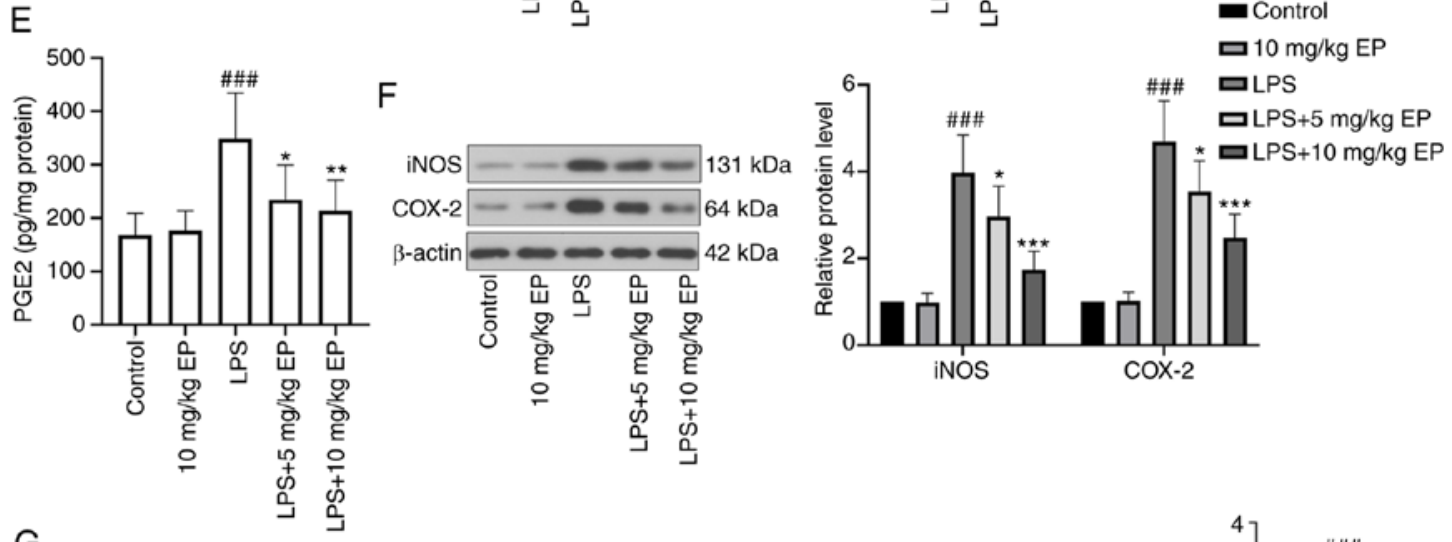

G

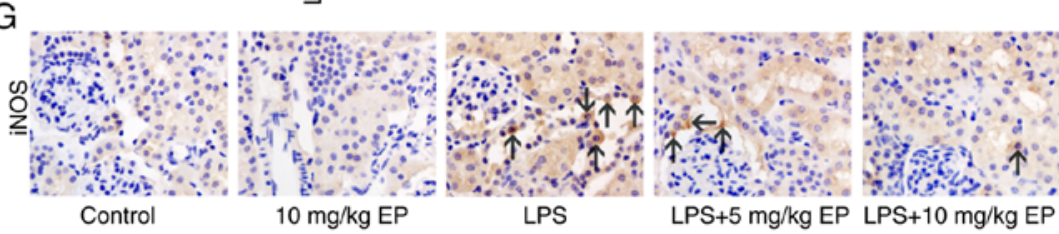

H
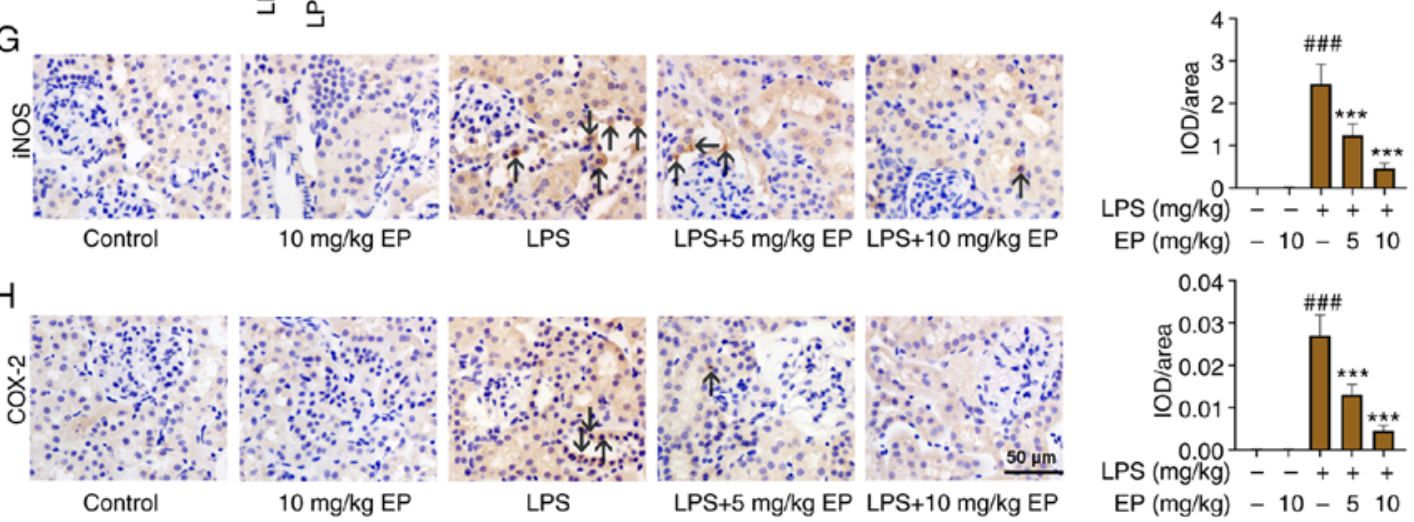

Figure 2. Effect of EP on renal tissue inflammation induced by LPS. Levels of (A) TNF- $\alpha$, (B) IL-1 $\beta$ and (C) IL-6 were evaluated in renal tissues using ELISA. (D) NO and (E) PGE2 content. (F) Protein expression levels of iNOS and COX-2. $\beta$-actin was used as the internal reference. Levels of (G) iNOS and (H) COX-2 evaluated using immunohistochemistry. Arrows represent iNOS/COX-2-positive cells. Results are presented as the mean \pm standard deviation $(\mathrm{n}=6) .{ }^{\# \# \#} \mathrm{P}<0.001$ vs. control group; ${ }^{*} \mathrm{P}<0.05,{ }^{* *} \mathrm{P}<0.01$ and ${ }^{* * *} \mathrm{P}<0.001$ vs. LPS group. EP, Echinacea polysaccharide; LPS, lipopolysaccharide; TNF- $\alpha$, tumor necrosis factor- $\alpha$; IL, interleukin; NO, nitric oxide; PGE2, prostaglandin E2; iNOS, inducible nitric oxide synthase; COX-2, Cycol-oxygenase-2.

using GraphPad Prism version 8.0 (GraphPad Software, Inc.). Comparisons between $\geq 3$ groups were performed using a one-way ANOVA followed by Tukey's post hoc test. $\mathrm{P}<0.05$ was considered to indicate a statistically significant difference.

\section{Results}

EP attenuates LPS-induced AKI in mice. The effects of EP on LPS-induced histological changes in the kidney tissues were 

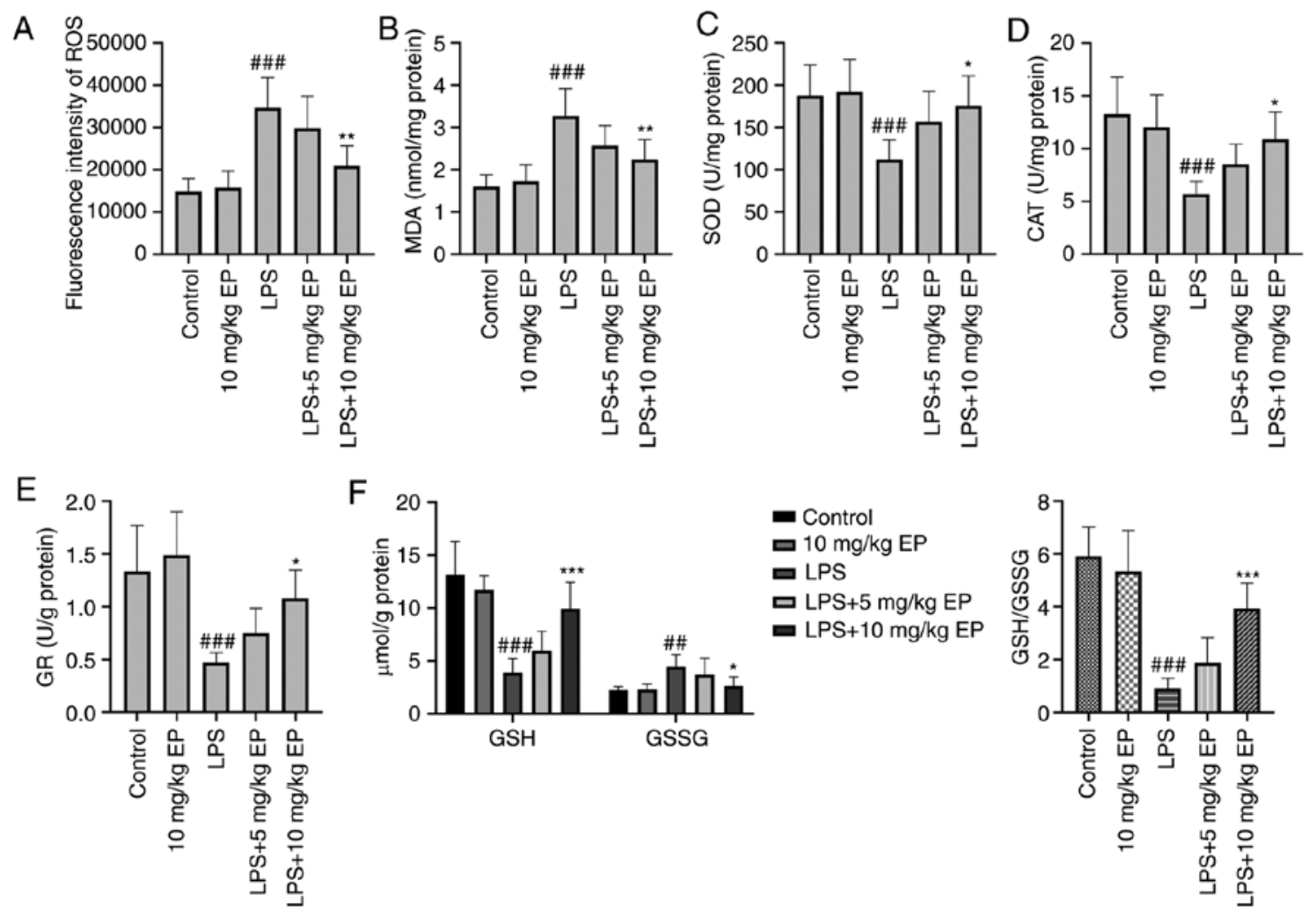

Figure 3. Effect of EP on renal tissue oxidative stress mediated by LPS. (A) Fluorescence intensity of ROS. (B) MDA, (C) SOD, (D) CAT and (E) GR contents, and (F) GSH and GSSG levels were detected using commercial kits. Results are presented as the mean \pm standard deviation $(\mathrm{n}=6)$. ${ }^{\# \#} \mathrm{P}<0.01$ and ${ }^{\# \# \#} \mathrm{P}<0.001$ vs. control group; ${ }^{*} \mathrm{P}<0.05,{ }^{* * *} \mathrm{P}<0.01$ and ${ }^{* * * *} \mathrm{P}<0.001$ vs. LPS group. EP, Echinacea polysaccharide; LPS, lipopolysaccharide; ROS, reactive oxygen species; MDA, malondialdehyde; SOD, superoxide dismutase; CAT, catalase; GR, glutathione reductase; GSH, reduced glutathione; GSSG, oxidized glutathione.

assessed using H\&E and PAS staining. Fig. 1A shows that inflammation was successfully induced by LPS and that the co-administration of EP significantly attenuated this process. As shown in Fig. 1B, the glomerular structure was intact, and no obvious pathological changes were observed in the control and $10 \mathrm{mg} / \mathrm{kg}$ EP-treated mice. By contrast, proliferation of mesangial cells, swelling of glomerular epithelial cells, interstitial edema and glycogen deposition were observed in the LPS-treated renal tissues. Pretreatment with EP markedly alleviated LPS-induced glomerular and tubular damage, and significantly decreased the number of PAS-positive cells. Additionally, the levels of BUN in the blood were elevated following LPS treatment for $24 \mathrm{~h}$ (Fig. 1C) compared with the control group. Similarly, Cr levels were also increased in LPS-treated mice (Fig. 1D). EP co-administration markedly decreased BUN and Cr levels.

EP represses inflammation in LPS-treated mice. The levels of indices of inflammation were measured to evaluate the effect of EP on the inflammatory response. As shown in Fig. 2A-E, TNF- $\alpha$, IL-1 $\beta$, IL-6, NO and PGE2 levels were significantly increased in the LPS-treated kidney tissues compared with in the control mice and were significantly decreased following EP treatment compared with the LPS group. Compared with the control group, the protein expression levels of iNOS and COX-2 were significantly upregulated by LPS treatment; however, pretreatment with EP decreased this upregulation (Fig. 2F). In addition, as shown in Fig. 2G and H, immunohistochemistry results for iNOS and COX-2 revealed that administration of EP decreased LPS-induced upregulation of iNOS and COX-2 in kidney tissues. Additionally, there were few or no iNOS and COX-2-positive cells in the control and EP-treated control mice.

EP decreases $O S$ induced by LPS in mice. To investigate the role of EP in OS, the levels of ROS and MDA, as well as SOD activity, were detected in kidney tissues. DCFH-DA is a fluorescent probe of ROS. As illustrated in Fig. 3A, the fluorescence intensity of the LPS group was significantly higher than that of the control group, indicating that the production of ROS in LPS-treated mice was increased. EP administration significantly decreased ROS generation compared with the LPS group. Furthermore, the LPS-treated group exhibited a significant increase in MDA and GSSG levels, and a significant decrease in SOD, CAT and GR levels, as well as GSH activity, compared with the control mice (Fig. 3B-F). Additionally, compared with in the control group, the ratio of GSH/GSSG was significantly decreased in the LPS-treated group. Administration of EP markedly attenuated these changes.

EP inhibits the activation of the MAPK signaling pathway in LPS-treated kidney tissues. To determine the effects of EP on the MAPK signaling pathway in renal tissues following LPS treatment, the expression levels of p-ERK, ERK, p-JNK, JNK, p-p38 and p38 were measured via western blotting. As shown in Fig. 4, the levels of p-ERK, p-JNK and p-p38 were significantly increased in LPS-treated kidneys compared with in the control 
A
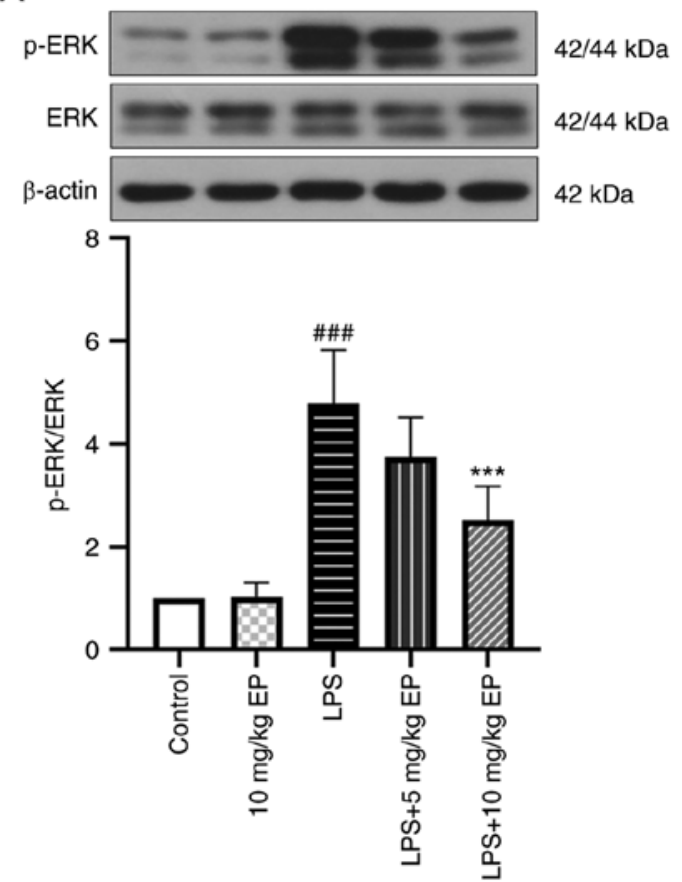

B
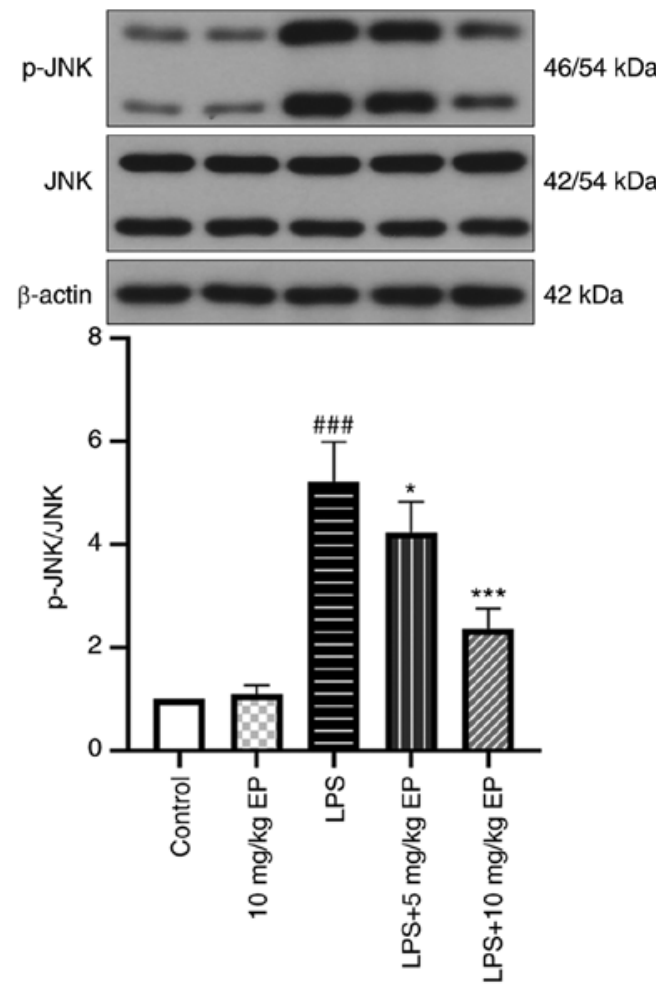
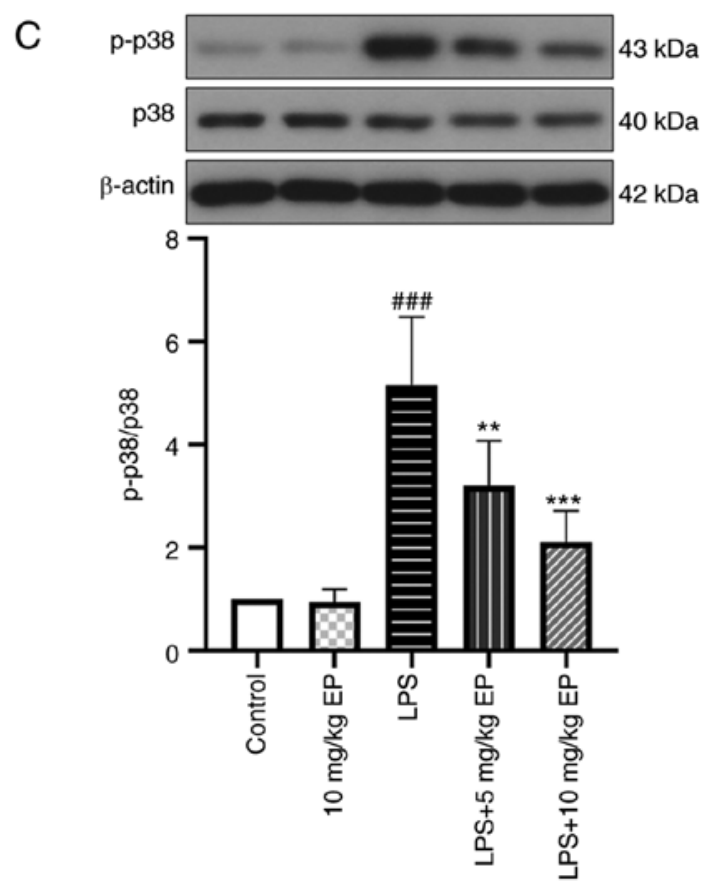

Figure 4. Effect of EP on the MAPK signaling pathway in LPS-treated kidney tissues. Protein levels of (A) p-ERK (Thr202/Tyr204) and ERK, (B) p-JNK (Thr183/Tyr185) and JNK, and (C) p-p38 (Thr180/Tyr182) and p38 were detected in renal tissues using western blotting. $\beta$-actin was used as the internal reference. Results are presented as the mean \pm standard deviation $(\mathrm{n}=6) .{ }^{\# \# \#} \mathrm{P}<0.001$ vs. control group; ${ }^{*} \mathrm{P}<0.05,{ }^{* *} \mathrm{P}<0.01$ and ${ }^{* * *} \mathrm{P}<0.001$ vs. LPS group. EP, Echinacea polysaccharide; LPS, lipopolysaccharide; MAPK, mitogen-activated protein kinase; p-, phospho-; ERK, extracellular signal-regulated protein kinase; JNK, c-Jun N-terminal kinase.

group. However, LPS-induced upregulation of p-ERK, p-JNK and p-p38 levels was attenuated by administration of EP (5 or $10 \mathrm{mg} / \mathrm{kg}$ ). Furthermore, there was no difference in ERK, JNK and p38 levels in the kidney irrespective of treatment.

EP mitigates LPS-mediated HBZY-1 cell damage. To further explore the role of EP in OS and inflammation in vitro, an LPS-treated HBZY-1 cell model was established. As shown in Fig. 5A, compared with the control cells, LPS significantly decreased HBZY-1 cell viability, whereas pretreatment with EP restored the viability of LPS-treated cells. Fig. 5B-G shows that EP decreased OS in LPS-treated cells as demonstrated by the lowered ROS, MDA and GSSG levels, and the elevated SOD, CAT and GR levels, as well as 

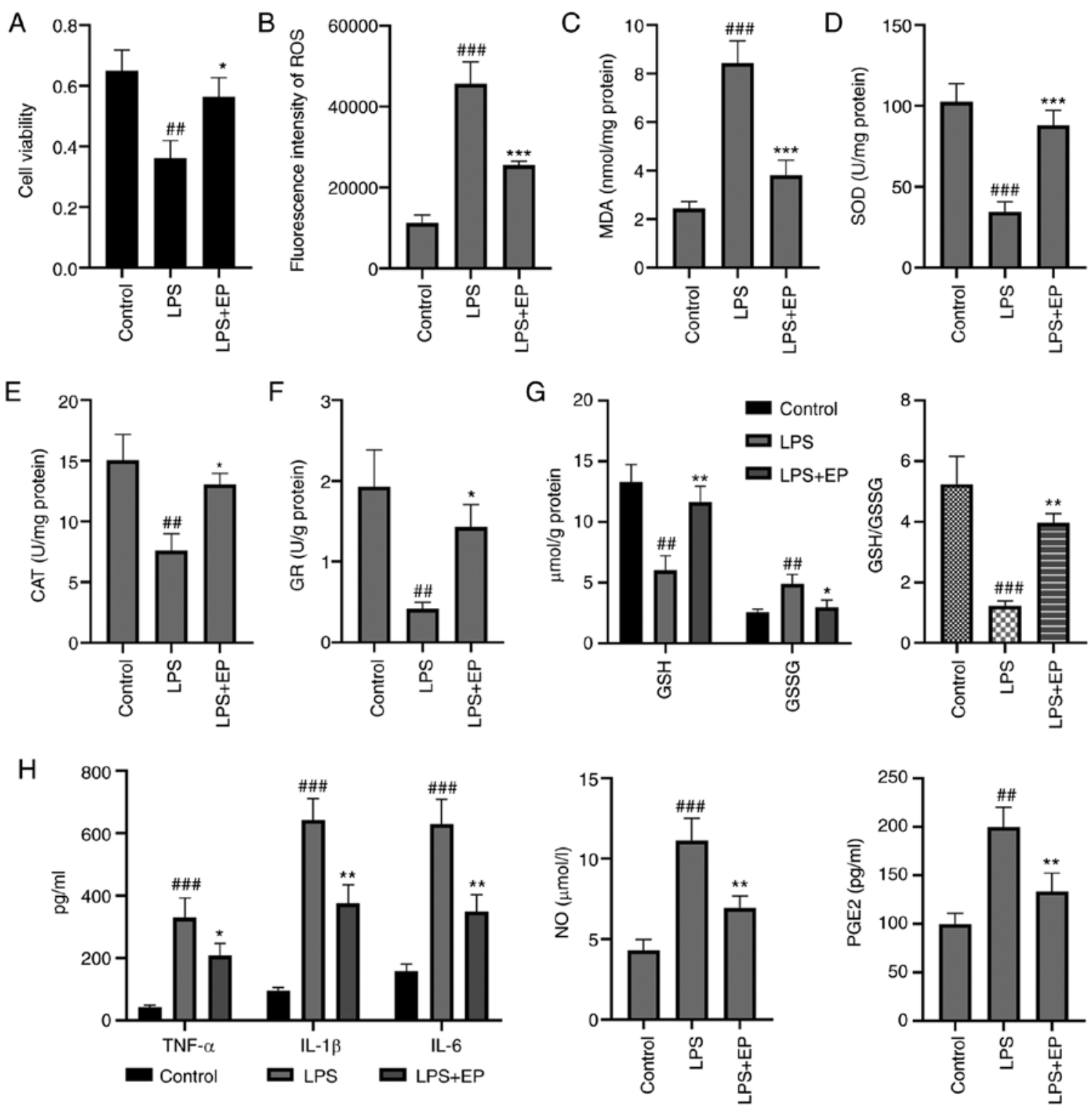

Figure 5. Effect of EP on LPS-treated HBZY-1 cells. (A) Cell viability was detected using an MTT assay. (B) Fluorescence intensity of ROS. (C) MDA, (D) SOD, (E) CAT and (F) GR levels, and (G) GSH and GSSG content were detected using commercial kits. (H) TNF- $\alpha$, IL-1 $\beta$, IL-6, NO and PGE2 levels. Results are presented as the mean \pm standard deviation $(\mathrm{n}=3)$. ${ }^{\# \#} \mathrm{P}<0.01$ and ${ }^{\# \# \#} \mathrm{P}<0.001$ vs. control group; ${ }^{*} \mathrm{P}<0.05,{ }^{* *} \mathrm{P}<0.01$ and ${ }^{* * *} \mathrm{P}<0.001$ vs. LPS group. EP, Echinacea polysaccharide; LPS, lipopolysaccharide; ROS, reactive oxygen species; MDA, malondialdehyde; SOD, superoxide dismutase; CAT, catalase; GR, glutathione reductase; GSH, reduced glutathione; GSSG, oxidized glutathione; TNF- $\alpha$, tumor necrosis factor- $\alpha$; IL, interleukin; NO, nitric oxide; PGE2, prostaglandin E2.

GSH contents, compared with the LPS group. Additionally, LPS treatment resulted in a significant increase in TNF- $\alpha$, IL-1 $\beta$, IL-6, NO and PGE2 contents compared with the control cells, while these levels were significantly decreased by co-administration of EP compared with the LPS-treated cells (Fig. 5H).

EP suppresses the MAPK signaling pathway in LPS-treated $H B Z Y-1$ cells. The effects of EP on proteins involved in the MAPK signaling pathway in HBZY-1 cells were investigated using western blotting. The expression levels of p-ERK, p-JNK and p-p38 were significantly higher in LPS-treated cells compared with in the control group, and these alterations were significantly attenuated by pretreatment with EP (Fig. 6A). Notably, immunofluorescence analysis revealed that EP markedly blocked nuclear translocation of p-ERK, p-JNK and p-p38 in LPS-treated cells (Fig. 6B). Additionally, cells were treated with EP, PD98095, SP600125 or SB203580 for $1 \mathrm{~h}$ and then treated with LPS for $24 \mathrm{~h}$. Cell viability and the indicators associated with OS and inflammation were evaluated. Cell viability was significantly decreased in the LPS group compared with in control cells and was significantly reversed with the administration of EP, PD98095, SP600125 or SB203580 (Fig. 6C). The results presented in Fig. 6D-I confirmed that the treatment with EP, PD98095, SP600125 or SB203580 attenuated OS through the significantly decreased levels of ROS and MDA, and the significantly increased SOD activity, as well as decreasing the inflammatory response as demonstrated by the significantly lower TNF- $\alpha$, IL-1 $\beta$ and IL- 6 levels compared with those in LPS-treated cells. Therefore, EP may exhibit its therapeutic effect in AKI via regulating the MAPK signaling pathway. However, the detailed mechanism requires further study. 


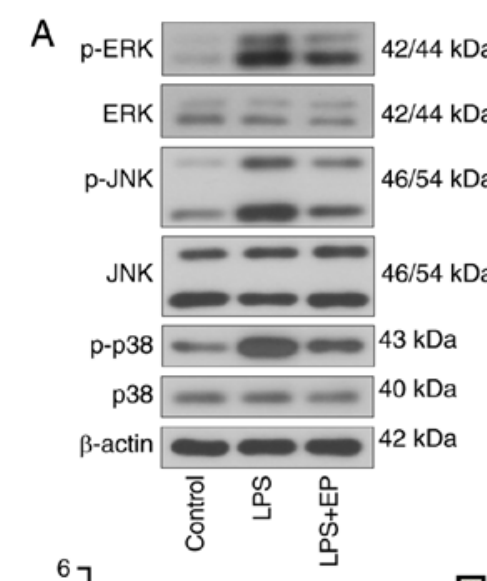

B
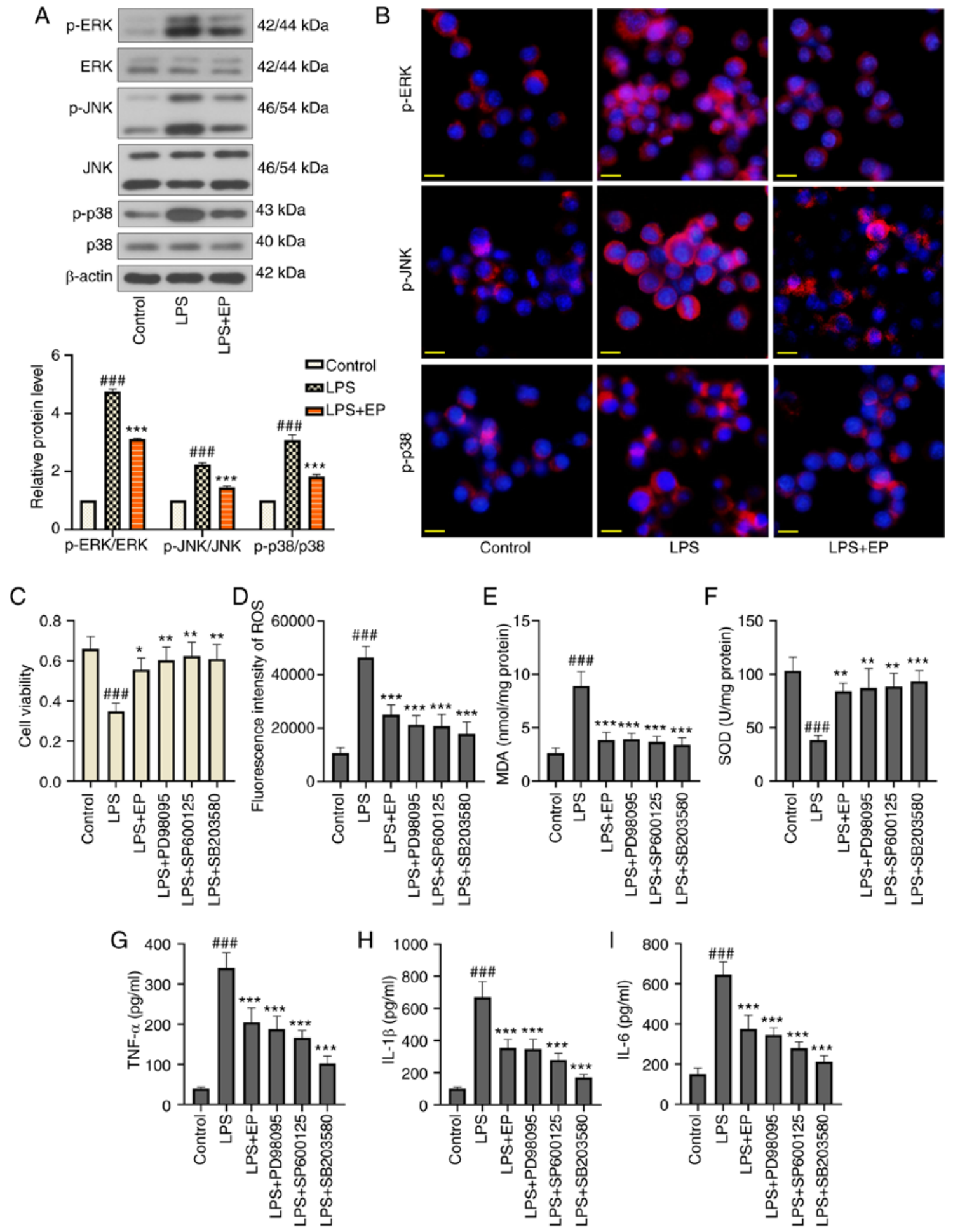

Figure 6. Effect of EP on the MAPK signaling pathway in LPS-treated HBZY-1 cells. (A) Protein levels of p-ERK (Thr202/Tyr204), ERK, p-JNK (Thr183/Tyr185), JNK, p-p38 (Thr180/Tyr182) and p38 were detected via western blotting. $\beta$-actin was used as the internal reference. (B) p-ERK, p-JNK and p-p38 expression levels were evaluated using immunofluorescence analysis. Scale bar, $50 \mu \mathrm{m}$. (C) An MTT assay was used to assess cell viability. (D) Fluorescence intensity of ROS. (E) MDA content and (F) SOD activity were detected using commercial kits. Levels of (G) TNF- $\alpha$, (H) IL-1 $\beta$ and (I) IL-6 were evaluated in cell supernatants using the corresponding kits. Results are presented as the mean \pm standard deviation $(\mathrm{n}=3)$. ${ }^{\# \# \#} \mathrm{P}<0.001 \mathrm{vs}$. control group; ${ }^{*} \mathrm{P}<0.05,{ }^{* *} \mathrm{P}<0.01$ and ${ }^{* * * *} \mathrm{P}<0.001$ vs. LPS group. EP, Echinacea polysaccharide; LPS, lipopolysaccharide; MAPK, mitogen-activated protein kinase; p-, phospho-; ERK, extracellular signal-regulated protein kinase; JNK, c-Jun N-terminal kinase; ROS, reactive oxygen species; MDA, malondialdehyde; SOD, superoxide dismutase; TNF- $\alpha$, tumor necrosis factor- $\alpha$; IL, interleukin.

\section{Discussion}

LPS treatment resulted in renal impairment in the present mouse model of AKI, and EP effectively mitigated the
LPS-mediated AKI. BUN and Cr are established biomarkers used for the diagnosis of AKI $(28,29)$. In the present study, there was a prominent decrease in the levels of BUN and $\mathrm{Cr}$ following EP administration in LPS-treated kidney tissues, 
in agreement with a previous study, which demonstrated that AKI was attenuated by podocyte-specific soluble epoxide hydrolase deficiency in mice and that BUN and Cr levels were decreased (30). Furthermore, the current histological analysis revealed that EP decreased LPS-induced AKI.

A previous study highlighted the importance of inflammation in burn-associated AKI (31). The inflammatory response is a complex biological process, which includes the synthesis and release of pro-inflammatory cytokines, such as TNF- $\alpha$, IL-1 $\beta$ and IL-6 (32). Additionally, LPS induces the release of TNF- $\alpha$ and IL-1 $\beta$ via a Toll-like receptor 4 pathway, resulting in increased OS (33). TNF- $\alpha$ serves an essential role in the development of AKI by activating kidney endothelial TNF receptor 1 (34). A recent study has indicated that IL-1 $\beta$ and IL-6 are important pro-inflammatory indicators in renal diseases (35), which accelerate NO release. Additionally, overproduction of NO generates peroxynitrite ions, directly or indirectly resulting in the damage of target cells and tissues (36). It has been demonstrated that enhanced renal NO levels significantly increase the expression levels of iNOS in glycerol-mediated AKI (37). Yu et al (36) reported that honokiol significantly decreased the expression levels of iNOS in a rat model of renal ischemia/reperfusion injury. COX-2, one of the downstream molecules of NO, was upregulated in mononuclear cells, endothelial cells and macrophages following elevated NO (38). Additionally, PGE2, the product of COX-2, is an essential inflammatory mediator (38). As described by Hwang et al (39), COX-2 and PGE2 serve critical roles in the pathogenesis of kidney inflammation. A previous study indicated that Aloe vera polysaccharides suppressed TNF- $\alpha$-induced secretion of inflammatory cytokines in $\mathrm{HaCaT}$ cells (40). Another study confirmed that EP exhibited anti-inflammatory properties in a rat model of colitis induced by acetic acid (41). Consistent with previous studies $(3,42)$, the anti-inflammatory effect of EP on LPS-induced AKI in the present study was achieved via decreasing the levels of inflammatory indicators in vivo and in vitro. Cellular injury and its associated molecular products serve as vital triggers in inflammation following acute tissue damage (6). Additionally, EP pretreatment in the present study increased cell viability in LPS-mediated HBZY-1 cells, which was similar to a previous study demonstrating that Maerkang Lactarius Deliciosus Gray polysaccharides promoted the proliferation of RAW264.7 cells (43).

OS serves an important role in the occurrence and development of AKI (44). It has been demonstrated that OS is enhanced in LPS-induced models of AKI (45) and that the MAPK signaling pathway is an essential modulator of altered gene transcription in response to increased OS (46). OS can be caused by an imbalance between ROS generation and anti-oxidant defense (47). Excessive ROS production is detrimental to cellular functions; it has been reported that ROS may damage biomolecules such as DNA, RNA, proteins and lipids (3), and may induce the release of inflammatory cytokines through activation of the $\mathrm{NF}-\kappa \mathrm{B}$ signaling pathway (48). The production of endogenous ROS activates ERK, while exogenous ROS generation results in p38 activation (46). Furthermore, MDA, the end product of unsaturated lipid peroxidation, has been widely utilized as a marker of oxidative damage (48). SOD, CAT, GR and GSH are vital antioxidant indicators modulating oxidative injury $(36,49)$.
The anti-oxidative status is closely associated with the ratio of GSH/GSSG (35). In the present study, ROS, MDA and GSSG levels were elevated, while SOD, CAT, GR and GSH activities were lowered in LPS-treated mice and cells. EP administration reversed these levels, similarly to previous studies $(4,50)$.

JNK may be activated by OS, and is considered vital for the regulation of oxidative damage (47). Additionally, p38 is able to participate in the progression and development of inflammation when tissues or cells are impaired (51). Following injury, the majority of inflammatory mediators, including TNF- $\alpha$, IL-1 $\beta$ and IL-6, are released (52). These molecules can act on JNK and p38, phosphorylating and activating them; subsequently, p-JNK and p-p38 are translocated to the nucleus resulting in a series of responses, such as oxidative injury, apoptosis and inflammatory responses (53-55). Additionally, the ERK signaling pathway is an important signaling pathway, of which the abnormal or dysregulated activation may lead to renal tissue impairment (56). The MAPK signaling pathway has been demonstrated to modulate pro-inflammatory cytokines, such as IL-1 $\beta$, in AKI (57). A previous study revealed that JNK, ERK and p38 where inactivated by hesperetin, suggesting that hesperetin may be used to inhibit inflammation in cisplatin-induced AKI (58). In the present study, ERK, JNK and p38 were notably activated by LPS in renal tissues and HBZY-1 cells. Notably, EP treatment decreased the expression levels of p-ERK, p-JNK and p-p38. The current findings suggest that EP may attenuate LPS-induced AKI in vivo and in vitro, potentially via inhibiting the activation of the MAPK signaling pathway, similarly to a previous study (5). However, another previous study demonstrated that a novel polysaccharide derived from algae extracts inhibited breast cancer progression via activation of the JNK signaling pathway (20), which is inconsistent with the results of the present study. This may be due to the different sources of polysaccharides, cell types and models. Additionally, the protein kinase B (Akt) signaling pathway serves a critical role in inflammatory and autoimmune diseases (59). A previous study revealed that Terminalia bellirica (Gaertn.) Roxb. extract decreased the inflammatory response and OS via activation of the Akt signaling pathway in an LPS-shock mouse model (60). Zhao et al (61) reported that dexmedetomidine protected against LPS-mediated AKI in rats via inhibiting the activation of the Akt signaling pathway. Additionally, another study demonstrated that water extracts from the roots of E. purpurea containing a polysaccharide with anti-inflammatory properties activated the Akt signaling pathway in human acute monocytic leukemia (THP-1) cells (62). Therefore, future studies should further investigate the effects of EP on the Akt signaling pathway in LPS-induced AKI.

A previous study indicated that the absorption of natural bioactive polysaccharides in the body was likely directly via the gut, gut microbiota or Peyer's patches (63). As suggested by $\mathrm{Yu}$ et al (64), pumpkin polysaccharides may be metabolized by various enzymes in the liver. Dendrobium aphyllum polysaccharides consist of mannose and glucose (65), and glucose metabolism is strongly involved in regulation of diabetes and immune responses. Possible metabolic pathways involved with polysaccharides include glucose dehydrogenase, glucose-6-phosphatase and glucose transporters (GLUT1 and 
GLUT2). Notably, the aforementioned studies provide some references for studying the in vivo metabolism of EP; however, the full mechanism of how EP is metabolized in vivo remains unknown. Therefore, the in vivo metabolism of EP, the effect of EP on other possible signaling pathways and the underlying mechanisms in LPS-induced AKI should be further investigated in future studies. The present study illustrated the inhibitory effect of EP on the MAPK signaling pathway, but how EP exerts its function in AKI via this signaling pathway and detailed mechanisms require further research.

In conclusion, the results of the present study clearly indicated that EP attenuated AKI by decreasing inflammation and OS. In addition, EP likely suppressed the activation of the MAPK signaling pathway via decreasing the protein expression levels of p-ERK, p-JNK and p-p38. Therefore, EP may be a potential therapeutic agent for the treatment of AKI, given its anti-inflammatory and anti-oxidative effects.

\section{Acknowledgements}

Not applicable.

\section{Funding}

The present study was supported by grants from the National Natural Science Foundation of China (grant no. 31472230), the Third Batch of Giant Project of Hebei Province (grant no. 180416), the Top Talent Project for Youths of Hebei Province (grant no. 180443), the Doctoral Startup Foundation of Hebei Normal University of Science and Technology (grant no. 2018YB018), the High School Hundred Excellent Innovation Talent Program of Hebei Province, the Natural Science Foundation of Hebei Province (grant no. C2019407111) and the Project of Department of Science and Technology of Hebei Province (grant no. 18246629G).

\section{Availability of data and materials}

All data generated or analyzed during this study are included in this published article.

\section{Authors' contributions}

HZ and QS contributed to the conception of the study. QS, WL and SW designed the experiments. GL, XB and XY performed the experiments. WL, SW and GL analyzed the data. QS drafted the manuscript. HZ revised the manuscript. All authors have read and approved the final manuscript.

\section{Ethics approval and consent to participate}

All animal studies and protocols were approved by the Animal Care Committee of Hebei Normal University of Science and Technology (approval no. 201823; 5 September 2018), and were performed according to the Committee's guidelines on animal care.

\section{Patient consent for publication}

Not applicable.

\section{Competing interests}

The authors declare that they have no competing interests.

\section{References}

1. Gonsalez SR, Cortês AL, Silva RCD, Lowe J, Prieto MC and Silva Lara LD: Acute kidney injury overview: From basic findings to new prevention and therapy strategies. Pharmacol Ther 200: 1-12, 2019.

2. Peters E, Geraci S, Heemskerk S, Wilmer MJ, Bilos A, Kraenzlin B, Gretz N, Pickkers P and Masereeuw R: Alkaline phosphatase protects against renal inflammation through dephosphorylation of lipopolysaccharide and adenosine triphosphate. Br J Pharmacol 172: 4932-4945, 2015.

3. Zhang H, Chen MK, Li K, Hu C, Lu MH and Situ J: Eupafolin nanoparticle improves acute renal injury induced by LPS through inhibiting ROS and inflammation. Biomed Pharmacother 85: 704-711, 2017.

4. Liu X, Lu J, Liao Y, Liu S, Chen Y, He R, Men L, Lu C, Chen Z, Li S, et al: Dihydroartemisinin attenuates lipopolysaccharide-induced acute kidney injury by inhibiting inflammation and oxidative stress. Biomed Pharmacother 117: 109070, 2019.

5. Liu Q, Chen Y, Shen C, Xiao Y, Wang Y, Liu Z and Liu X: Chicoric acid supplementation prevents systemic inflammation-induced memory impairment and amyloidogenesis via inhibition of NF-кB. FASEB J 31: 1494-1507, 2017.

6. Rabb H, Griffin MD, McKay DB, Swaminathan S, Pickkers P Rosner MH, Kellum JA and Ronco C; Acute Dialysis Quality Initiative Consensus XIII Work Group: Inflammation in AKI: Current understanding, key questions, and knowledge gaps. J Am Soc Nephrol 27: 371-379, 2016.

7. Li HD, Meng XM, Huang C, Zhang L, Lv XW and Li J: Application of herbal traditional Chinese medicine in the treatment of acute kidney injury. Front Pharmacol 10: 376, 2019.

8. Islam MS, Miao L, Yu H, Han Z and Sun H: Ethanol extract of Illicium henryi attenuates LPS-induced acute kidney injury in mice via regulating inflammation and oxidative stress. Nutrients 11: 1412, 2019.

9. Karsch-Völk M, Barrett B and Linde K: Echinace a for preventing and treating the common cold. JAMA 313: 618-619, 2015.

10. Tubaro A, Tragni E, Del Negro P, Galli CL and Della Loggia R: Anti-inflammation activity of a polysaccharidic fraction of Echinacea angustifolia. J Pharm Pharmacol 39: 567-569, 1987.

11. Sharifi-Rad M, Mnayer D, Morais-Braga MFB, Carneiro JNP, Bezerra CF, Coutinho HDM, Salehi B, Martorell M, Del Mar Contreras M, Soltani-Nejad A, et al: Echinacea plants as antioxidant and antibacterial agents: From traditional medicine to biotechnological applications. Phytother Res 32: 1653-1663, 2018.

12. Hall C III: Echinacea as a functional food ingredient. Adv Food Nutr Res 47: 113-173, 2003.

13. Oláh A, Szabó-Papp J, Soeberdt M, Knie U, Dähnhardt-Pfeiffer S, Abels C and Bíró T: Echinacea purpurea-derived alkylamides exhibit potent anti-inflammatory effects and alleviate clinical symptoms of atopic eczema. J Dermatol Sci 88: 67-77, 2017.

14. Ghaemi A, Soleimanjahi H, Gill P, Arefian E, Soudi S and Hassan Z: Echinacea purpurea polysaccharide reduces the latency rate in herpes simplex virus type-1 infections. Intervirology 52: 29-34, 2009.

15. Hudson JB: Applications of the phytomedicine Echinacea purpurea (Purple Coneflower) in infectious diseases. J Biomed Biotechnol 2012: 769896, 2012.

16. Yang G, Li K, Liu C, Peng P, Bai M, Sun J, Li Q, Yang Z, Yang Y and $\mathrm{Wu} \mathrm{H}$ : A comparison of the immunostimulatory effects of polysaccharides from tetraploid and diploid Echinacea purpurea. Biomed Res Int 2018: 8628531, 2018.

17. Aarland RC, Bañuelos-Hernández AE, Fragoso-Serrano M, Sierra-Palacios ED, Díaz de León-Sánchez F, Pérez-Flores LJ, Rivera-Cabrera F and Mendoza-Espinoza JA: Studies on phytochemical, antioxidant, anti-inflammatory, hypoglycaemic and antiproliferative activities of Echinacea purpurea and Echinacea angustifolia extracts. Pharm Biol 55: 649-656, 2017.

18. Kim EK and Choi EJ: Compromised MAPK signaling in human disease: An update. Arch Toxicol 89: 867-882, 2015.

19. Santulli P, Marcellin L, Tosti C, Chouzenoux S, Cerles O, Borghese B, Batteux F and Chapron C: MAP kinases and the inflammatory signaling cascade as targets for the treatment of endometriosis? Expert Opin Ther Targets 19: 1465-1483, 2015. 
20. Xie P, Horio F, Fujii I, Zhao J, Shinohara M and Matsukura M: A novel polysaccharide derived from algae extract inhibits cancer progression via JNK, not via the p38 MAPK signaling pathway. Int J Oncol 52: 1380-1390, 2018.

21. Sherif IO, Al-Mutabagani LA, Alnakhli AM, Sobh MA and Mohammed HE: Renoprotective effects of angiotensin receptor blocker and stem cells in acute kidney injury: Involvement of inflammatory and apoptotic markers. Exp Biol Med (Maywood) 240: 1572-1579, 2015.

22. Sahu BD, Mahesh Kumar J and Sistla R: Baicalein, a bioflavonoid, prevents cisplatin-induced acute kidney injury by up-regulating antioxidant defenses and down-regulating the MAPKs and NF-кB pathways. PLoS One 10: e0134139, 2015.

23. Han C, Sun T, Liu Y, Fan G, Zhang W and Liu C: Protective effect of Polygonatum sibiricum polysaccharides on gentamicin-induced acute kidney injury in rats via inhibiting p38 MAPK/ATF2 pathway. Int J Biol Macromol 151: 595-601, 2020.

24. Li G, Fu J, Zhao Y, Ji K, Luan T and Zang B: Alpha-lipoic acid exerts anti-inflammatory effects on lipopolysaccharide-stimulated rat mesangial cells via inhibition of nuclear factor kappa $\mathrm{B}(\mathrm{NF}-\mathrm{\kappa} \mathrm{B})$ signaling pathway. Inflammation 38: 510-519, 2015.

25. Yuan J, Hou K, Yao Y, Du Z, Lu C, Yuan Q and Gao X: Gold clusters attenuate inflammation in rat mesangial cells via inhibiting the activation of NF- $\mathrm{BB}$ pathway. Nanomaterials (Basel) 10: $712,2020$.

26. Hou R, Xu T, Li Q, Yang F, Wang C, Huang T and Hao Z: Polysaccharide from Echinacea purpurea reduces the oxidant stress in vitro and in vivo. Int J Biol Macromol 149: 41-50, 2020.

27. Beckert H, Meyer-Martin H, Buhl R, Taube $\mathrm{C}$ and Reuter S The canonical but not the noncanonical Wnt pathway inhibits the development of allergic airway disease. J Immunol 201: $1855-1864,2018$

28. Burmeister DM, Gómez BI and Dubick MA: Molecular mechanisms of trauma-induced acute kidney injury: Inflammatory and metabolic insights from animal models. Biochim Biophys Acta Mol Basis Dis 1863: 2661-2671, 2017.

29. Teo SH and Endre ZH: Biomarkers in acute kidney injury (AKI) Best Pract Res Clin Anaesthesiol 31: 331-344, 2017.

30. Bettaieb A, Koike S, Chahed S, Zhao Y, Bachaalany S, Hashoush N, Graham J, Fatima H, Havel PJ, Gruzdev A, et al: Podocyte-specific soluble epoxide hydrolase deficiency in mice attenuates acute kidney injury. FEBS J 284: 1970-1986, 2017.

31. Clark A, Neyra JA, Madni T, Imran J, Phelan H, Arnoldo B and Wolf SE: Acute kidney injury after burn. Burns 43: 898-908, 2017.

32. Gan Y, Tao S, Cao D, Xie H and Zeng Q: Protection of resveratrol on acute kidney injury in septic rats. Human Exp Toxicol 36: 1015-1022, 2017

33. Chen Y, Jin S, Teng X, Hu Z, Zhang Z, Qiu X, Tian D and Wu Y: Hydrogen sulfide attenuates LPS-induced acute kidney injury by inhibiting inflammation and oxidative stress. Oxid Med Cell Longev 2018: 6717212, 2018

34. Xu C, Chang A, Hack BK, Eadon MT, Alper SL and Cunningham PN: TNF-mediated damage to glomerular endothelium is an important determinant of acute kidney injury in sepsis. Kidney Int 85: 72-81, 2014.

35. Sharma M, Naura AS and Singla SK: Modulatory effect of 4-phenyl butyric acid on hyperoxaluria-induced renal injury and inflammation. Mol Cell Biochem 451: 185-196, 2019.

36. Yu Y, Li M, Su N, Zhang Z, Zhao H, Yu H and Xu Y: Honokiol protects against renal ischemia/reperfusion injury via the suppression of oxidative stress, iNOS, inflammation and STAT3 in rats. Mol Med Rep 13: 1353-1360, 2016.

37. Liu Y, Fu X, Gou L, Li S, Lan N, Zheng Y and Yin X: L-citrulline protects against glycerol-induced acute renal failure in rats. Ren Fail 35: 367-373, 2013.

38. Zhao H, Liu Z, Shen H, Jin S and Zhang S: Glycyrrhizic acid pretreatment prevents sepsis-induced acute kidney injury via suppressing inflammation, apoptosis and oxidative stress. Eur J Pharmacol 781: 92-99, 2016.

39. Hwang HS, Yang KJ, Park KC, Choi HS, Kim SH, Hong SY, Jeon BH, Chang YK, Park CW, Kim SY, et al: Pretreatment with paricalcitol attenuates inflammation in ischemia-reperfusion injury via the up-regulation of cyclooxygenase-2 and prostaglandin E2. Nephrol Dial Transplant 28: 1156-1166, 2013.

40. Leng H, Pu L, Xu L, Shi X, Ji J and Chen K: Effects of aloe polysaccharide, a polysaccharide extracted from Aloe vera, on TNF- $\alpha$-induced HaCaT cell proliferation and the underlying mechanism in psoriasis. Mol Med Rep 18: 3537-3543, 2018
41. Dogan Z, Ergul B, Sarikaya M, Filik L, Gonultas MA, Hucumenoglu S and Can M: The protective effect of Echinacea spp. (Echinacea angustifolia and Echinacea purpurea) in a rat colitis model induced by acetic acid. Pak J Pharm Sci 27: $1827-1835,2014$

42. Mirzoyan K, Denis C, Casemayou A, Gilet M, Marsal D, Goudounéche D, Faguer S, Bascands JL, Schanstra JP and Saulnier-Blache JS: Lysophosphatidic acid protects against endotoxin-induced acute kidney injury. Inflammation 40: 1707-1716, 2017.

43. Su S, Ding X, Fu L and Hou Y: Structural characterization and immune regulation of a novel polysaccharide from maerkang Lactarius deliciosus gray. Int J Mol Med 44: 713-724, 2019.

44. Tomsa AM, Alexa AL, Junie ML, Rachisan AL and Ciumarnean L: Oxidative stress as a potential target in acute kidney injury. PeerJ 7: e8046, 2019.

45. Rousta AM, Mirahmadi SM, Shahmohammadi A, Nourabadi D, Khajevand-Khazaei MR, Baluchnejadmojarad T and Roghani M: Protective effect of sesamin in lipopolysaccharide-induced mouse model of acute kidney injury via attenuation of oxidative stress, inflammation, and apoptosis. Immunopharmacol Immunotoxicol 40: 423-429, 2018.

46. Chatterjee A and Chatterji U: All-trans retinoic acid ameliorates arsenic-induced oxidative stress and apoptosis in the rat uterus by modulating MAPK signaling proteins. J Cell Biochem 118: 3796-3809, 2017

47. Chenxu G, Minxuan X, Yuting Q, Tingting G, Jinxiao L, Mingxing W, Sujun W, Yongjie M, Deshuai L, Qiang L, et al: iRhom 2 loss alleviates renal injury in long-term PM2.5-exposed mice by suppression of inflammation and oxidative stress. Redox Biol 19: 147-157, 2018

48. Sun Q, Xin F, Wen X, Lu C, Chen R and Ruan G: Protective effects of different kinds of filtered water on hypertensive mouse by suppressing oxidative stress and inflammation. Oxid Med Cell Longev 2018: 2917387, 2018.

49. Sahu BD, Kuncha M, Sindhura GJ and Sistla R: Hesperidin attenuates cisplatin-induced acute renal injury by decreasing oxidative stress, inflammation and DNA damage. Phytomedicine 20: 453-460, 2013.

50. Jia P, Wu X, Pan T, Xu S, Hu J and Ding X: Uncoupling protein 1 inhibits mitochondrial reactive oxygen species generation and alleviates acute kidney injury. EBioMedicine 49: 331-340, 2019.

51. Amos LA, Ma FY, Tesch GH, Liles JT, Breckenridge D, Nikolic-Patersn DJ and Han Y: ASK1 inhibitor treatment suppresses $\mathrm{p} 38 / \mathrm{JNK}$ signalling with reduced kidney inflammation and fibrosis in rat crescentic glomerulonephritis. J Cell Mol Med 22: 4522-4533, 2018.

52. Ma Y,Zhao Q, Shao Y, Cao MZ, Zhao M and Wang D: Melatonin inhibits the inflammation and apoptosis in rats with diabetic retinopathy via MAPK pathway. Eur Rev Med Pharmacol Sci 23 (Suppl 3): S1-S8, 2019.

53. Zhu L, Yi X, Zhao J, Yuan Z, Wen L, Pozniak B, Obminska-Mrukowicz B, Tian Y, Tan Z, Wu J and Yi J: Betulinic acid attenuates dexamethasone-induced oxidative damage through the JNK-P38 MAPK signaling pathway in mice. Biomed Pharmacother 103: 499-508, 2018.

54. Xing Y, Yang SD, Wang MM, Dong F, Feng YS and Zhang F: Electroacupuncture alleviated neuronal apoptosis following ischemic stroke in rats via midkine and ERK/JNK/p38 signaling pathway. J Mol Neurosci 66: 26-36, 2018.

55. Chen S, Zhao L, Sherchan P, Ding Y, Yu J, Nowrangi D, Tang J, Xia Y and Zhang JH: Activation of melanocortin receptor 4 with RO27-3225 attenuates neuroinflammation through AMPK/JNK/p38 MAPK pathway after intracerebral hemorrhage in mice. J Neuroinflammation 15: 106, 2018.

56. Gupta KK, Donahue DL, Sandoval-Cooper MJ, Castellino FJ and Ploplis VA: Abrogation of plasminogen activator inhibitor1-vitronectin interaction ameliorates acute kidney injury in murine endotoxemia. PLoS One 10: e0120728, 2015

57. Shen WC, Liang CJ, Huang TM, Liu CW, Wang SH, Young GH, Tsai JS, Tseng YC, Peng YS, Wu VC and Chen YL: Indoxyl sulfate enhances IL-1 $\beta$-induced E-selectin expression in endothelial cells in acute kidney injury by the ROS/MAPKs/NFkB/AP-1 pathway. Arch Toxicol 90: 2779-2792, 2016.

58. Chen X, Wei W, Li Y, Huang J and Ci X: Hesperetin relieves cisplatin-induced acute kidney injury by mitigating oxidative stress, inflammation and apoptosis. Chem Biol Interact 308: 269-278, 2019. 
59. Nitulescu GM, Van De Venter M, Nitulescu G, Ungurianu A, Juzenas P, Peng Q, Olaru OT, Gradinaru D, Tsatsakis A, Tsoukalas D, et al: The Akt pathway in oncology therapy and beyond (Review). Int J Oncol 53: 2319-2331, 2018.

60. Tanaka M, Kishimoto Y, Sasaki M, Sato A, Kamiya T, Kondo K and Iida K: Terminalia bellirica (Gaertn.) Roxb. extract and gallic acid attenuate LPS-induced inflammation and oxidative stress via MAPK/NF- $\kappa \mathrm{B}$ and Akt/AMPK/Nrf2 pathways. Oxid Med Cell Longev 2018: 9364364, 2018.

61. Zhao Y, Feng X, Li B, Sha J, Wang C, Yang T, Cui H and Fan H: Dexmedetomidine protects against lipopolysaccharide-induced acute kidney injury by enhancing autophagy through inhibition of the PI3K/AKT/mTOR pathway. Front Pharmacol 11: 128, 2020

62. Fast DJ, Balles JA, Scholten JD, Mulder T and Rana J: Echinacea purpurea root extract inhibits TNF release in response to Pam3Csk4 in a phosphatidylinositol-3-kinase dependent manner. Cell Immunol 297: 94-99, 2015.
63. Han QB: Critical problems stalling progress in natural bioactive polysaccharide research and development. J Agric Food Chem 66: 4581-4583, 2018

64. Yu M, Xiao B, Hao X, Tan J, Gu J, Wang G, Wang W and Zhang Y: Pumpkin polysaccharide preparation, stimulated gastrointestinal digestion, and in vivo biodistribution. Int J Biol Macromol 141: 1293-1303, 2019.

65. Liu H, Ma L and Wang Q: Possible metabolic pathway of a novel bioactive polysaccharide extracted from Dendrobium aphyllum: An in vivo study. J Food Sci 84: 1216-1223, 2019.

(7) This work is licensed under a Creative Commons Attribution-NonCommercial-NoDerivatives 4.0 International (CC BY-NC-ND 4.0) License. 